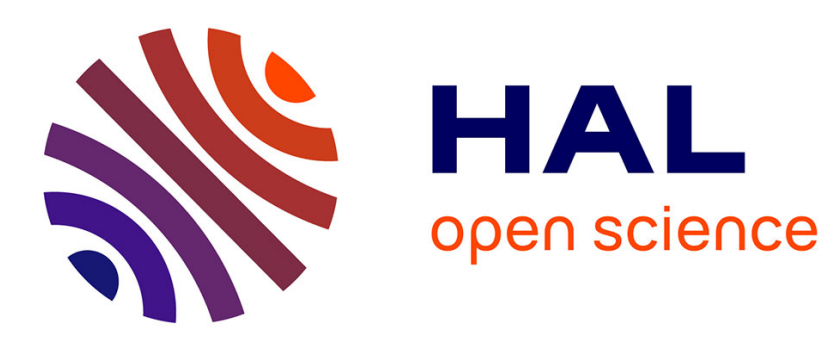

\title{
Efficient assessment of topographic solar radiation to improve plant distribution models
}

Christian Piedallu, Jean-Claude Gégout

\section{To cite this version:}

Christian Piedallu, Jean-Claude Gégout. Efficient assessment of topographic solar radiation to improve plant distribution models. Agricultural and Forest Meteorology, 2008, 148 (11), pp.1696-1706. 10.1016/j.agrformet.2008.06.001 . hal-00835905

\section{HAL Id: hal-00835905 https://hal.science/hal-00835905}

Submitted on 20 Jun 2013

HAL is a multi-disciplinary open access archive for the deposit and dissemination of scientific research documents, whether they are published or not. The documents may come from teaching and research institutions in France or abroad, or from public or private research centers.
L'archive ouverte pluridisciplinaire HAL, est destinée au dépôt et à la diffusion de documents scientifiques de niveau recherche, publiés ou non, émanant des établissements d'enseignement et de recherche français ou étrangers, des laboratoires publics ou privés. 


\title{
Efficient assessment of topographic solar radiation to improve plant distribution models
}

\author{
Christian Piedallu *, Jean-claude Gégout \\ * Corresponding author. Tel.: +333833968 77; fax: +33 383396878 . \\ E-mail address: christian.piedallu@agroparistech.fr
}

\begin{abstract}
Plant ecologists have recognized the importance of solar radiation for decades but have difficulty measuring it on plots. Proxies recorded on the ground or geographical information system (GIS) indices processed with a digital elevation model (DEM) have generally been used. Here we compare the efficiency of different methods of estimating spatially distributed topographic solar radiation, from the simplest ones (proxies based on slope, and sine or cosine transformed values of aspect) to more elaborate ones using a GIS program suited to calculations of monthly clear sky and overcast solar radiation. We used a 50-metre DEM to estimate solar radiation with these different methods for the whole of France $\left(550000 \mathrm{~km}^{2}\right.$ ). Radiation indices were compared with ground measurements from meteorological stations and used to model the distribution of silver fir (Abies alba), sycamore (Acer pseudoplatanus), and downy oak (Quercus pubescens), forest species known to be sensitive to light. Results show that sine and cosine of aspect, combined or not with slope, are inefficient at simulating solar radiation over large areas. Solar radiation, calculated for clear sky and especially including cloud cover, is more relevant, leading respectively to an $\mathrm{R}^{2}$ of 0.46 and 0.78 between measured and predicted annual radiation. Calculation with cloud cover appears to be the most efficient index for improving distribution models for the three species studied. Slope and aspect transformations are less efficient than the GIS calculations, but the difference between these proxies decreased on a local scale. Using both with GIS solar radiation, cosine of aspect, with or without interaction with slope, slightly improves distribution models on a local scale, but this effect attenuates with increase in area studied. We conclude that the effect of proxies studied is scale-dependent, but GIS-based calculation including cloudiness variability is more appropriate than topographic proxies or clear sky models in estimating solar radiation and improving the efficiency of plant distribution models.
\end{abstract}

Keywords: solar radiation, topographic proxies, geographical information system (GIS), digital elevation model (DEM), plant distribution models, vegetation modelling. 


\subsection{Introduction}

Vegetation studies require accurate data over extensive areas in order to model species distribution on the scale of their distribution area (Guisan and Thuiller, 2005). This is made possible by the development of large databases (Brisse et al., 1995; Gégout et al., 2005), improvements in sampling methods (Elith et al., 2006) and computing capacity. Solar radiation plays an important role in the distribution, composition, and productivity of ecosystems through photosynthetic activity (Satterlund and Means, 1978; Gates, 1980) and contributes to several parameters of the water balance (including air and soil heating, evapotranspiration, wind, snow and ice melt.) (Lebourgeois and Piedallu, 2005; Pierce et al., 2005). Many authors have sought to link solar radiation and the distribution or the productivity of plant species or communities (Franklin, 1998; Tappeiner et al., 1998; Zimmermann and Kienast, 1999; Meentemeyer et al., 2001; Dirnbock et al., 2003).

Modelling plant distribution commonly requires information on both the presence and absence of species, recorded on the ground, and values of ecological factors in the same plots. These explanatory factors can be recorded in the field or obtained by combination with GIS data layers. Measuring long-term solar radiation directly on plots is unrealistic over large areas, due to the number of plots necessary to establish relevant distribution models (Coudun and Gegout, 2006a). Few ground meteorological stations record these data, which are among the climatological values least frequently measured (Pierce et al., 2005; Yang et al., 2006).

Researchers have therefore used other methods to estimate radiation on plots. The simplest is to use proxies based on slope or aspect, which are based on local differences in radiation. These variables are often used because they are easy to measure or calculate (Carroll et al., 1999; Clark et al., 1999). Aspect being a circular variable, ecologists use a sine or cosine transformation to obtain a continuous gradient, stressing the north-south or east-west gradient (northness or eastness). The sine or cosine-transformed aspect values can be recorded on the ground or determined by GIS indices processed with a DEM (Austin et al., 1990; Pierce et al., 2005). Development of GIS technology since the early 1990s has enabled researchers to elaborate more sophisticated models of solar radiation (Wilson and Gallant, 2000; Kang et al., 2002). These provide geographical information for any point of the study site, using different more or less simplified methods of calculation. They are recognised to be in general cost-efficient and well suited to topographically complex areas (Rich et al., 1995b; Hofierka and Suri, 2002), and are commonly used in ecological studies (Guisan et al., 1998; Zimmermann and Kienast, 1999).

The efficiency of these methods of radiation estimation has received little attention, although they have been used in many ecological studies, and important differences have already been noted between different data sources (Aber and Freuder, 2000). Slope and aspect 
transformations represent an indirect gradient related to distribution of vegetation, and their effect is principally presumed to be linked to solar radiation (Austin, 2002). These proxies do not include effect of latitude and cloud on sunshine duration, and the same radiation value could arise from different combinations of slope and aspect when large areas are considered. However, they are considered interesting because they are generated without much loss of precision compared with biophysical indices (Guisan and Zimmermann, 2000). Solar radiation calculated with GIS models represents direct gradients having physiological effects on plants and is preferable to indirect gradients, the source of correlation with vegetation having been identified (Austin, 2002). However, different programs are used for solar radiation calculations, with variable success (Kang et al., 2002), making comparisons difficult. Many of them do not consider large-scale modulators like variations in cloud cover, and the effect of this simplification for predictive modelling has been little studied. The predictive ability of these different indices in modelling plant distribution is incompletely defined and previous studies have encountered difficulties in establishing the best explanatory variable to predict vegetation patterns, from slope or aspect transformed indices or potential solar radiation (Franklin et al., 2000; Miller and Franklin, 2002). Some authors also argue that solar radiation is not enough to describe vegetation/environment correlations and that microclimate represented by aspect and slope must be considered (Austin, 2005).

The aim of this study was to compare different methods of solar radiation estimation, to evaluate their contribution to measurements and their efficiency in plant distribution models. Five methods of calculation were used, i) sine transformation of aspect, ii) cosine transformation of aspect, iii) interaction between slope and cosine of aspect, iv) cloud-free solar radiation model, v) solar calculation modelled using cloud cover values. We used the Helios program (Piedallu and Gégout, 2007) to model solar radiation. We chose this program because it takes into account both local topographical (slope, aspect, shadowing) and global parameters (latitude, cloud cover), and requires few, easy-to-obtain input parameters: only DEM and cloud cover values from meteorological ground stations are needed. We compared these different methods in order to estimate i) if solar radiation calculated with GIS models performs better than slope-aspect transformations, ii) for the GIS models, if the method of calculation or the period considered have an influence on the results, iii) if the predictive ability of the different proxies is scale-dependent, iv) if the use of slope-aspect transformations enhances the species distribution models that include GIS processed solar radiation.

The five different solar radiation indices were implemented for France $\left(550000 \mathrm{~km}^{2}\right)$ at the finest available resolution covering the whole country $(50 * 50 \mathrm{~m}$ grid resolution). To assess their quality, modelled radiation data were compared with a dataset of measured values collected from meteorological stations. Their ability to predict species distribution was then evaluated by modelling on different scales the distribution of three plant species known to be sensitive to light: silver fir (Abies alba), sycamore (Acer pseudoplatanus $)$, and downy oak (Quercus pubescens). 


\subsection{Methods}

\subsubsection{Estimation of solar radiation}

Slope and aspect were derived from the French National Geographic Institute (IGN) Digital Elevation Model at $50 \mathrm{~m}$ resolution with ArcGIS 9.0 software. Aspect was converted to linear measures of eastness and northness by sine and cosine transformation. Cosine of aspect was then multiplied by slope to include inclination variability in the proxy.

Helios, a GIS program (Piedallu and Gégout, 2007), was used to estimate clear sky (Helios) and overcast solar radiation (Helios-c). This program computes hourly shortwave radiation by adding direct, diffuse, and terrain-reflected components (Duguay, 1993; Dubayah and Rich, 1995). The calculation is determined by three groups of factors: geometric relations between the sun and the earth's surface, topographic factors, and atmospheric attenuation (Gates, 1980). Geometric relations between the sun and the earth's surface are calculated with astronomic formulae, involving variations of solar radiation with time and location. Topographic factors are calculated using a DEM to characterise the angle of incidence of insolation. Sky obstruction by surrounding topography is simulated by determining the projection of a luminous ray on the DEM, limiting direct radiation in mountainous terrain by shadowing. Atmospheric attenuation due to gases and solid or liquid particles depends on the thickness of the atmosphere, and is calculated according to altitude, which can be determined with a good level of precision (Hetrick et al., 1993b; Wilson and Gallant, 2000).

Many programs used in plant ecology calculate solar radiation for clear sky, although clouds greatly attenuate the values (Dubayah and Loechel, 1997; Hofierka and Suri, 2002). In Helios, attenuation by clouds is considered separately, allowing the use of different sources of data. The overcast conditions are calculated using empirical equations based on extrapolation of average monthly cloud cover measured at ground meteorological stations, the cloud attenuation factor being defined by Kasten and Czeplak (1980).

\subsubsection{Evaluation of the five solar radiation indices}

The five radiation indices (sine and cosine of aspect, combination between slope and cosine of aspect, clear sky and overcast solar radiation) were calculated for the whole of France $\left(540000 \mathrm{~km}^{2}\right)$ at the $50 * 50 \mathrm{~m}$ resolution. In order to reduce computer time, solar radiation was calculated for each month of the year by interpolating monthly values from the median day for each of the 12 months. A cell by cell analysis on the 50 meter square grid was 
used to calculate coefficient of determination $\left(\mathrm{R}^{2}\right)$ between the different estimations for the whole of France.

The five calculation methods were compared with solar radiation measured in meteorological stations of the Météo France network. We selected 88 weather stations distributed throughout France, not including those used for the cloud cover calculations, and located with an accuracy of 100 metres. They range from 0 to $2780 \mathrm{~m}$ in altitude, from 0 to 38 degrees in slope, and cover all aspects. The decadal values were collected over the period 1971-2002 and were aggregated to calculate monthly averages in order to be compared with radiation indices. The selected stations have a minimum of 5 years of recording for each decade studied. The quality of the five estimations was evaluated by the determination coefficient $\left(\mathrm{R}^{2}\right)$ between measured and calculated values.

\subsubsection{Effect of different solar radiation estimations in plant distribution models}

To estimate if the different methods of solar radiation estimation could improve vegetation models, we modelled plant distribution with stepwise logistic regression for three forest species known to be sensitive to light: silver fir (Abies alba), sycamore ( $\underline{\text { Acer }}$ pseudoplatanus), and downy oak (Quercus pubescens). Silver fir is a 35-45 m coniferous tree, common in the mountain ranges of France and Europe, and sycamore is a 20-30 m deciduous tree, principally distributed in continental Europe and eastern France. These two species are known to be reliant on atmospheric moisture (Rameau et al., 1993). Downy oak is a 10-25 m sub-Mediterranean heliophilous and thermophilous tree, present in the southern two thirds of France.

The presence/absence of these tree species was extracted from the EcoPlant (Gégout et al., 2005) and Sophy (Brisse et al., 1995) databases, which store plots with floristic inventories from all over France, located with 5 to $1000 \mathrm{~m}$ precision (Figure 3.7). We used a sample of 6184 plots stratified according to latitude (3 strata: $41-45^{\circ}, 45-47.5^{\circ}, 47.5,51^{\circ}$ ), slope and aspect ( 3 strata: slope less than $5^{\circ}$, more than $5^{\circ}$ in north slope ranging between $270^{\circ}$ and $90^{\circ}$, more than $5^{\circ}$ in south slopes ranging between $90^{\circ}$ and $270^{\circ}$ ). This stratification meant that there was approximately the same number of plots on each slope, aspect, and latitude ranges. Plots too close to each other were eliminated in order to ensure a minimum distance of $1000 \mathrm{~m}$ between plots and thus avoid problems in distribution modelling linked to spatial autocorrelation (Diniz-Filho et al., 2003). For France, prevalence of sycamore is 13\%, downy oak $14.5 \%$, and silver fir $19 \%$ in the dataset. 
In order to detect an effect of scale, different levels of analysis were defined, covering the range of scales classically observed for plant distribution modelling studies. The first one is the whole of France $\left(550000 \mathrm{~km}^{2}\right)$, which is divided into four parts of similar area to give level 2, (about $130000 \mathrm{~km}^{2}$ ) (Figure 3.7). Level 3 is obtained by splitting one part of level 2 into four (about $32000 \mathrm{~km}^{2}$ per site), and for level 4 the same operation is achieved with one part of level 3 (about $8000 \mathrm{~km}^{2}$ per site). We then obtained 13 study sites organised on 4 levels of decreasing size area. From the 6184 plots available at level 1, the number of remaining plots range from 717 to 2357 for level 2, from 375 to 764 for level 3, and from 146 to 229 for level 4, depending on the area considered.

Coordinates of the plots were intersected with GIS layers to obtain a dataset containing binary values showing presence or absence of the three studied species, and values of ecological factors including the five indices of radiation. The ecological response of silver fir, sycamore, and downy oak was derived from logistic regression, one case of a generalised linear model (GLM) family, and one of the techniques most frequently used to model species distribution (McCullagh and Nelder, 1997; Guisan and Zimmermann, 2000; Austin et al., 2006). This method characterises the probability of occurrence of the species according to one or more environmental predictors. The goodness of fit was evaluated by calculating AUC, the area under the receiver operating characteristic curve (Fielding and Bell, 1997). We first defined the ecological response of the studied species according to the five different solar radiation indices for each geographical scale. Quadratic terms of the predictors were systematically used to consider curvilinear responses. Models were generated only when the number of occurrences exceeded 20. For clear sky and overcast Helios calculations, temporal variability was considered by examination of monthly and annual value effects. 

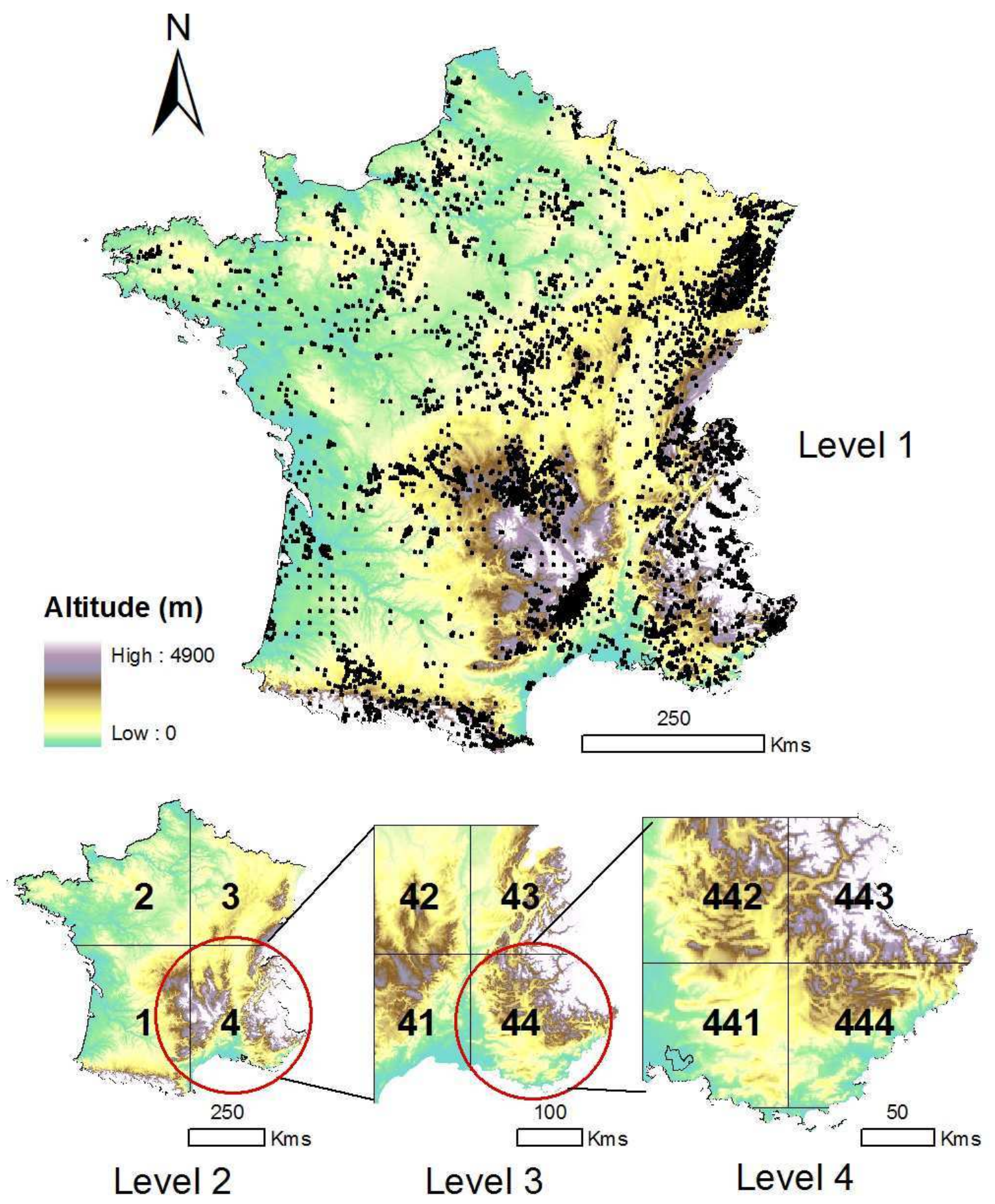

Figure 3.7: Location of the four levels of analysis used to evaluate predictive ability of the five solar radiation indices. Each level is divided successively into four parts in order to study species distribution across geographical scales. Black dots represent the location of the 6184 plots used to model plant distribution. 
In order to analyse if solar radiation adds a complementary effect to other environmental variables, we modelled plant response according to each of the radiation indices added to four important ecological variables (Franklin, 1995; Thuiller et al., 2003; Moser et al., 2005): mean annual temperature (MaT), mean annual precipitation (MaP), altitude, and soil $\mathrm{pH}$. These variables were extracted from four GIS data layers: AURELHY model at $1 \mathrm{~km}^{2}$ resolution for MaT and MaP (Benichou and Le Breton, 1987), DEM from the French Geographic Institute (IGN) at $50 \mathrm{~m}$ resolution for altitude, and $\mathrm{pH}$ from unpublished maps drawn up with plant indicator values and used successfully to predict Acer campestre and Vaccinium myrtillus distribution (Gégout et al., 2003; Coudun et al., 2006a; Coudun and Gegout, 2007). A forward stepwise procedure was used to select the most relevant of these studied variables. For each one, the variable with its quadratic form was tested. The simple form of the variable (monotonic form) was then selected when the quadratic form was not significant $(\mathrm{p}<0.001)$. The procedure was continued until adding a new variable did not produce a significant increase in the explained deviance. Finally GIS solar radiation indices were added to other environmental variables simultaneously with each of the topographic variables (i.e. eastness, northness, and interaction between northness and slope) in order to evaluate if both the proxies enhance plant distribution models.

\subsection{Results}

\subsubsection{Calculation and mapping of the solar radiation indices}

Eastness, northness, interaction between northness and slope, monthly and annual values of solar radiation with and without cloud cover, were calculated for France and mapped. An extract of maps showing the western part of the Alps highlights the importance of topographic conditions in mountainous areas (Figure 3.8). On the scale of France, maps of solar radiation, with and without cloud cover, show a latitudinal gradient with a radiation increase from north to south (Figure 3.9). Annual radiation calculated without cloud cover (Helios) ranged from 1400 to $8000 \mathrm{MJ} / \mathrm{m}^{2}$, with a mean value of $5200 \mathrm{MJ} / \mathrm{m}^{2}$. Annual values calculated with cloud cover (Helios-c) are logically lower, ranging from 1200 to $7200 \mathrm{MJ} / \mathrm{m}^{2}$, with a mean value of $4500 \mathrm{MJ} / \mathrm{m}^{2}$. The effect of cloud cover accentuates latitudinal effect and longitudinal variations. For example, regional climate such as high insolation in the Provence area is highlighted (noted A in the Helios-c map), as compared with the relatively low insolation of the Basque region at the same latitude (noted B) (Figure 3.9). 

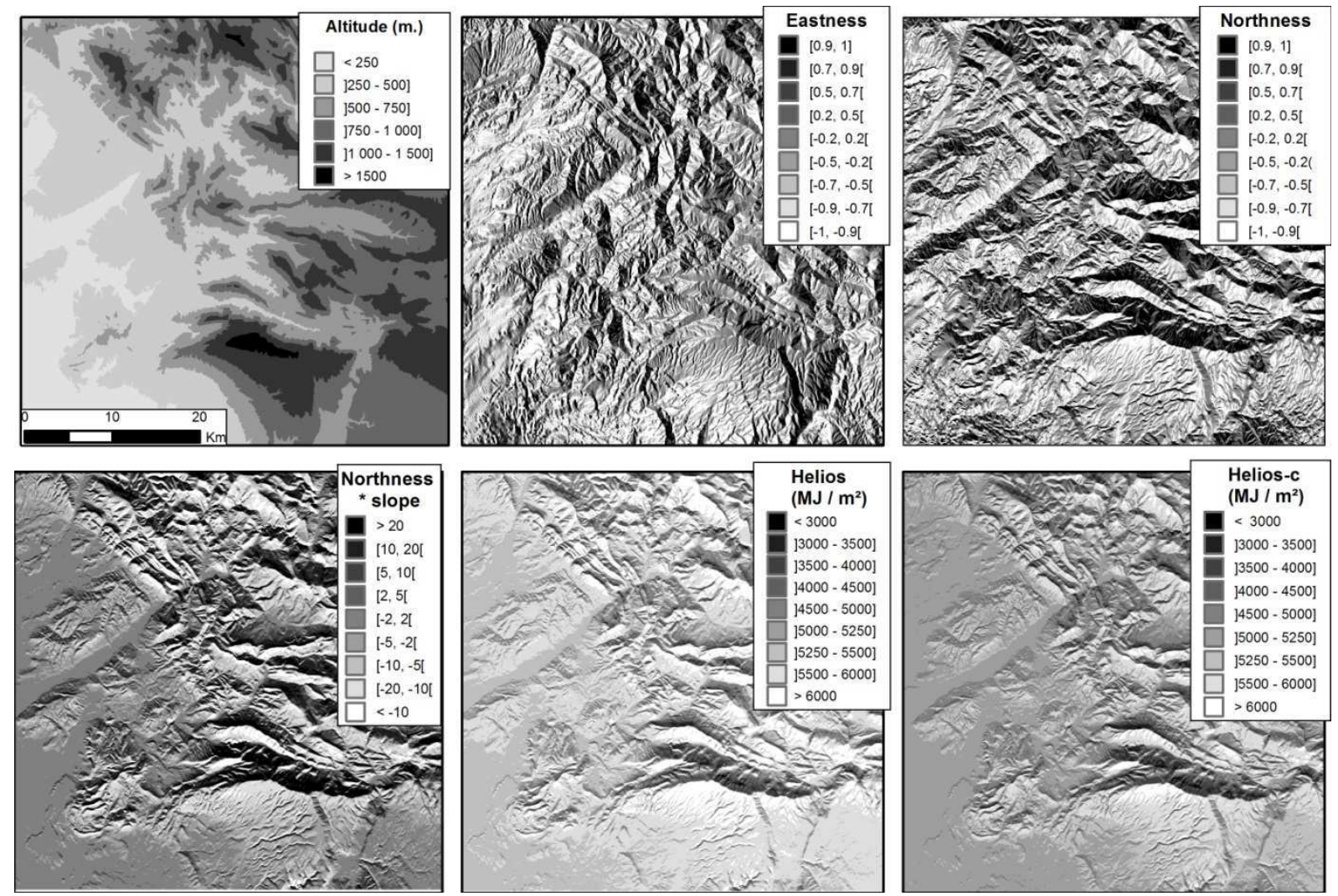

Figure 3.8: Sections of the national maps centred on the western Alps, showing different indices of solar radiation in rugged terrain. The calculations of eastness, northness, interaction between northness and slope, clear sky and overcast calculation with Helios (respectively Helios and Helios-c) are mapped.

Correlations between sine of aspect and the other radiation indices are very low for France $\left(\mathrm{R}^{2}\right.$ less than 0.02). They are higher between annual solar radiation simulated with Helios using cloud cover and cosine of aspect $\left(\mathrm{R}^{2}=0.36\right)$, or interaction between cosine of aspect and slope $\left(\mathrm{R}^{2}=0.62\right)$. The clear sky Helios model is more linked to topographical proxies than the overcast one $: \mathrm{R}^{2}$ is 0.83 with interaction between cosine of aspect and slope (it was 0.62 with the overcast model). Interaction between cosine of aspect and slope is the best measure that can be recorded on the ground correlated with modelled solar radiation on a nationwide level. The maximal correlation is reached between annual values calculated by Helios, with and without cloud cover $\left(\mathrm{R}^{2} 0.89\right)$. On a local scale, correlations between the GIS model and topographical proxies increase: for example $\mathrm{R}^{2}$ is 0.93 between Helios-c and interaction between cosine of aspect and slope for $8000 \mathrm{~km}^{2}$ areas (level 4) compared to 0.62 on a national scale. 


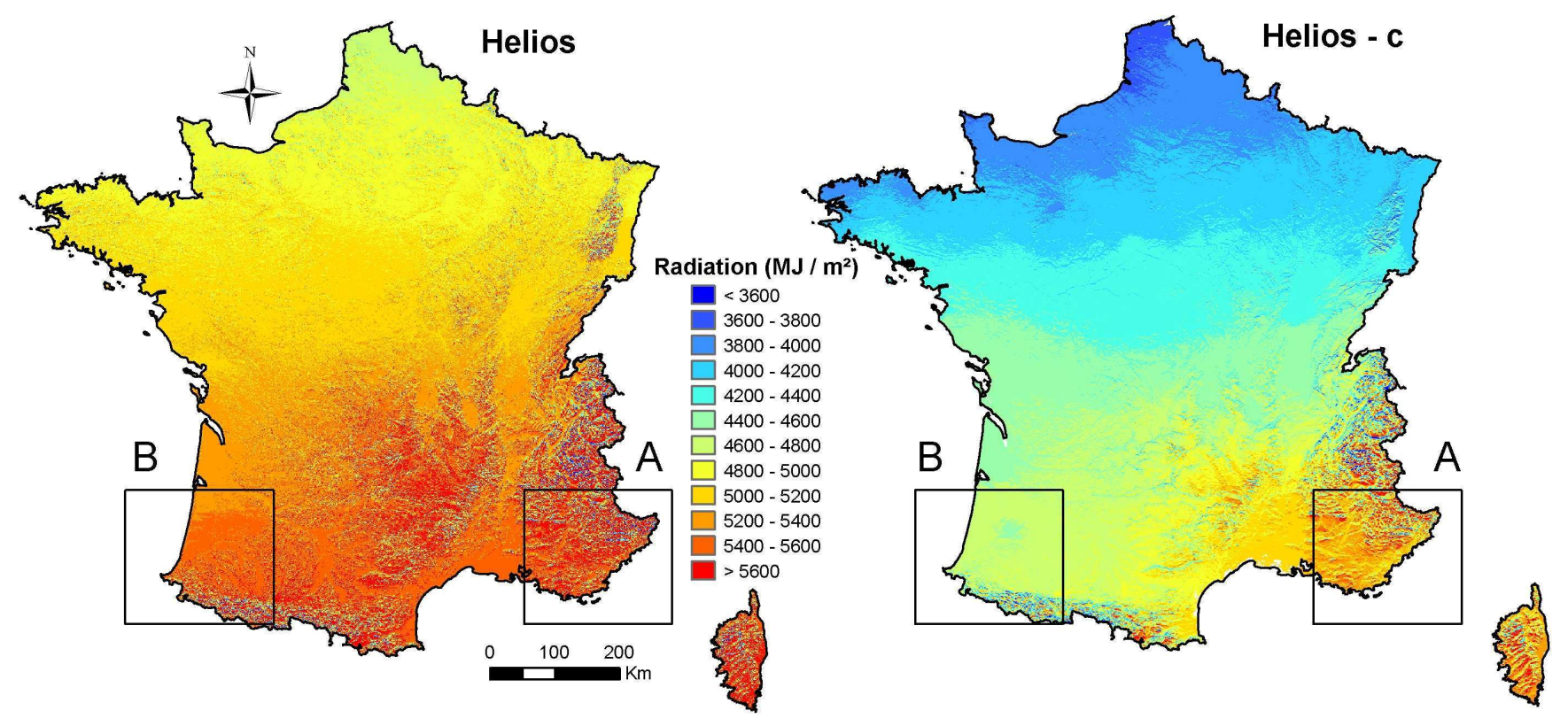

Figure 3.9: Annual solar radiation in France, calculation for clear sky (Helios) and overcast sky (Helios-c) $\left(M J / \mathrm{m}^{2}\right)$. A: Provence with high irradiation, B: Basque region at same latitude with lower irradiation showed by Helios-c.

\subsubsection{Relation between measurement and the different indices of solar radiation}

Correlations between indices and measurements of solar radiation made on a national scale differ greatly depending on the method used. Sine of aspect, cosine of aspect, with and without interaction with slope, show a very weak link with Météo France measurements (maximum $\mathrm{R}^{2}=0.02$, Table 3.5 ). The solar radiation calculated without cloud cover shows higher correlation, but a lower one than the overcast calculation, for monthly and annual values ( $\mathrm{R}^{2}$ 0.78, against 0.46 for clear sky radiation). The correlation between the Helios models and the measured values shows important variability depending on the period considered, the estimation being better in winter than in the other seasons. For the clear sky model, $\mathrm{R}^{2}$ values ranged from 0 in June to 0.76 for December, while overcast model, $\mathrm{R}^{2}$ ranged from 0.60 in May to 0.88 in December. 


\begin{tabular}{l|ccccccccccccc}
\hline & Jan. & Feb. & March & April & May & June & July & August & Sept. & October & Nov. & Dec. & Annual \\
\hline Eastness & 0.01 & 0.00 & 0.00 & 0.00 & 0.00 & 0.00 & 0.00 & 0.00 & 0.00 & 0.01 & 0.02 & 0.01 & 0.00 \\
Northness & 0.01 & 0.01 & 0.01 & 0.00 & 0.00 & 0.01 & 0.01 & 0.00 & 0.01 & 0.01 & 0.01 & 0.01 & 0.01 \\
North * slope & 0.01 & 0.01 & 0.01 & 0.00 & 0.00 & 0.02 & 0.01 & 0.01 & 0.01 & 0.01 & 0.01 & 0.01 & 0.01 \\
Helios & 0.72 & 0.62 & 0.53 & 0.29 & 0.01 & 0.00 & 0.12 & 0.25 & 0.46 & 0.58 & 0.68 & 0.76 & 0.46 \\
Helios-c & 0.88 & 0.84 & 0.81 & 0.60 & 0.60 & 0.62 & 0.68 & 0.65 & 0.72 & 0.78 & 0.84 & 0.88 & 0.78 \\
\hline
\end{tabular}

Table 3.5: Coefficient of determination $\left(R^{2}\right)$ between measured solar radiation for France (88 Météo France ground stations) and five radiation indices: eastness, northness, interaction between northness and slope, solar radiation estimated without cloud cover (Helios) and including cloud cover (Helios-c)

The clear sky model presents a mean absolute error of $778.8 \mathrm{MJ} / \mathrm{m}^{2}$ and a mean annual bias of $750.9 \mathrm{MJ} / \mathrm{m}^{2}$, representing an overestimation of the ground measurement of $14 \%$ (Figure 3.10). Taking cloud into account, bias drops to $30.9 \mathrm{MJ} / \mathrm{m}^{2}$ (less than $1 \%$ ) and the mean absolute error to $194.5 \mathrm{MJ} / \mathrm{m}^{2}$. When cloud cover is not taken into account, radiation at only 7 ground stations is underestimated. Radiation of the others is largely overestimated, 73 of them exceeding $500 \mathrm{MJ} / \mathrm{m}^{2}$ for annual values. Including cloud cover in the calculation, only $7 \%$ of stations present an annual variation exceeding $10 \%$ around the measured mean annual value. 10 Météo France stations located in the Mediterranean basin are underestimated, probably due to cloudiness overestimation or an albedo effect.
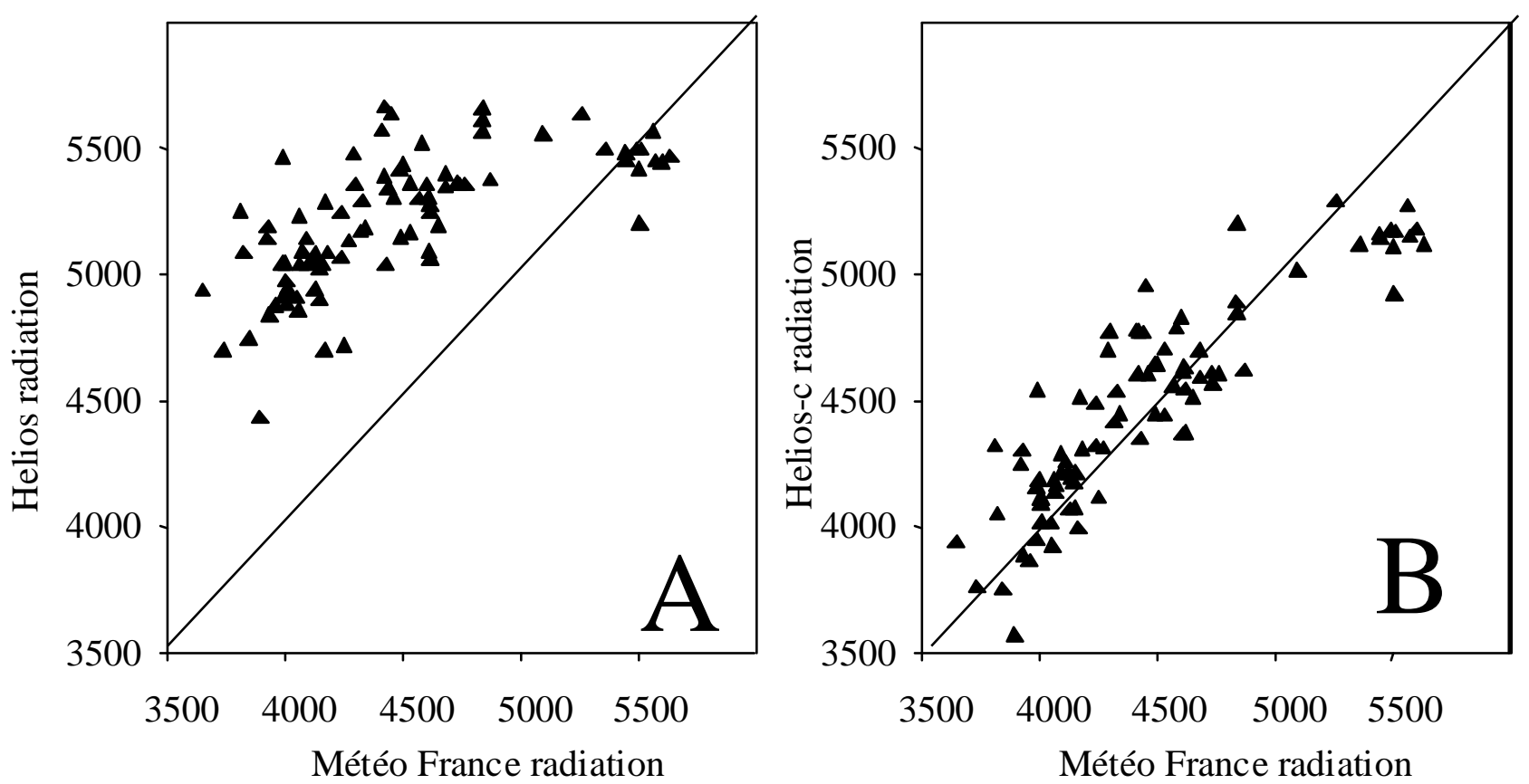

Figure 3.10: Relationship between annual solar radiation measured for 88 Météo France stations scattered throughout France and Helios values ignoring cloud (A) and including cloud $(B)\left(M J / m^{2}\right)$ 
We analysed the five radiation indices with a subset of eleven ground stations with a slope of more than $5^{\circ}$. Correlation remained very low for slope-aspect transformations, not exceeding an $\mathrm{R}^{2}$ of 0.02 with annual values of measured radiation. We found a marked decrease in correlation for annual values without cloud cover, with an $\mathrm{R}^{2}$ of 0.13 which can be compared with 0.46 for the set of all ground stations, and a smaller decrease for the cloudcover model with an $\mathrm{R}^{2}$ of 0.50 reduced from 0.78 .

\subsubsection{Effect of solar radiation indices on plant distribution modelling}

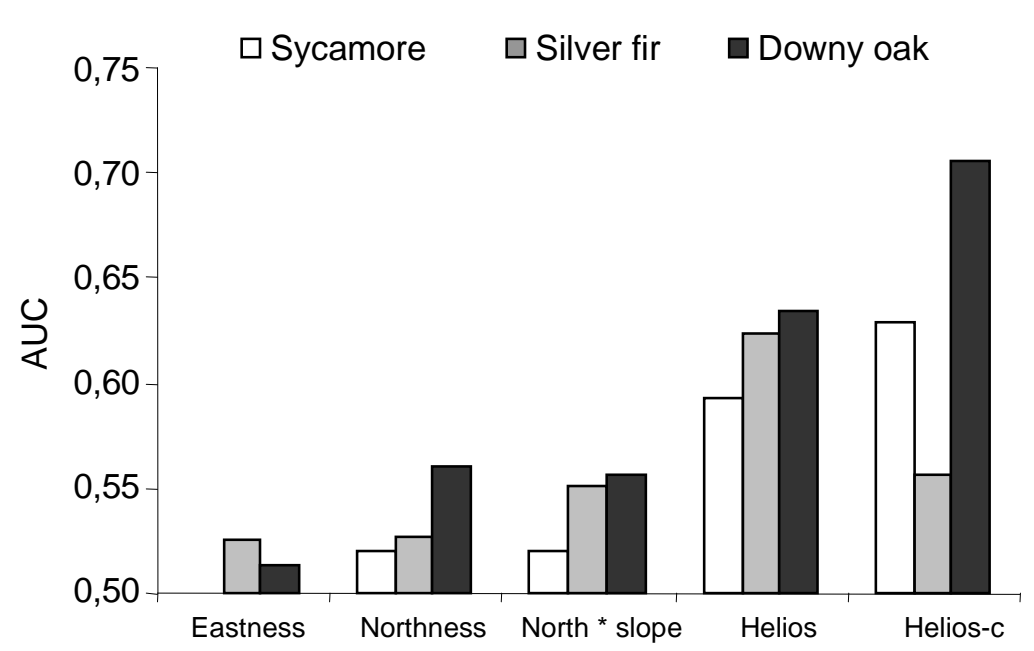

Figure 3.11: AUC for the univariate distribution models for sycamore, silver fir, and downy oak $(n=6184)$ derived on a national scale for France. Eastness, northness, interaction between northness and slope, solar radiation for clear sky (Helios) and including cloud (Helios-c) for the entire year are successively evaluated.

Univariate models between irradiation proxies and the three species distribution show that slope and aspect transformations were poorly relevant on a nationwide scale (Figure 3.11). These indices have consistently lower AUC than the annual values obtained with the GIS-based models. The highest ability to predict sycamore and downy oak distribution was observed with annual Helios-c (AUC values respectively 0.63 and 0.71 ). For silver fir, the best prediction was obtained using the Helios annual clear sky values (AUC $=0.62$ ). The response of sycamore and silver fir to solar radiation is decreasing, whereas the response of downy oak is increasing, according to the ecological knowledge of this species (Rameau et al., 1989; Rameau et al., 1993). The better performance of GIS calculated solar radiation compared with slope-aspect transformations was observed for each geographical scale studied (Figure 3.12), except for downy oak at the most reduced area (level 4, $8000 \mathrm{~km}^{2}$ ). Except for the eastness variable, which was always inefficient whatever the scale, the differences 
between the estimations dropped with the decrease in the area studied, both between the Helios model and slope-aspect transformations, and between the clear sky and the cloud cover GIS models. The better performance of the clear sky model compared with the model including cloud, observed on a national scale for silver fir, was not confirmed when considering more reduced areas. Northness and interaction between northness and slope were the best of the slope-aspect indices and their predictive ability seems to be relatively similar. Their effectiveness is close to that of solar radiation models when studying $8000 \mathrm{~km}^{2}$ areas.
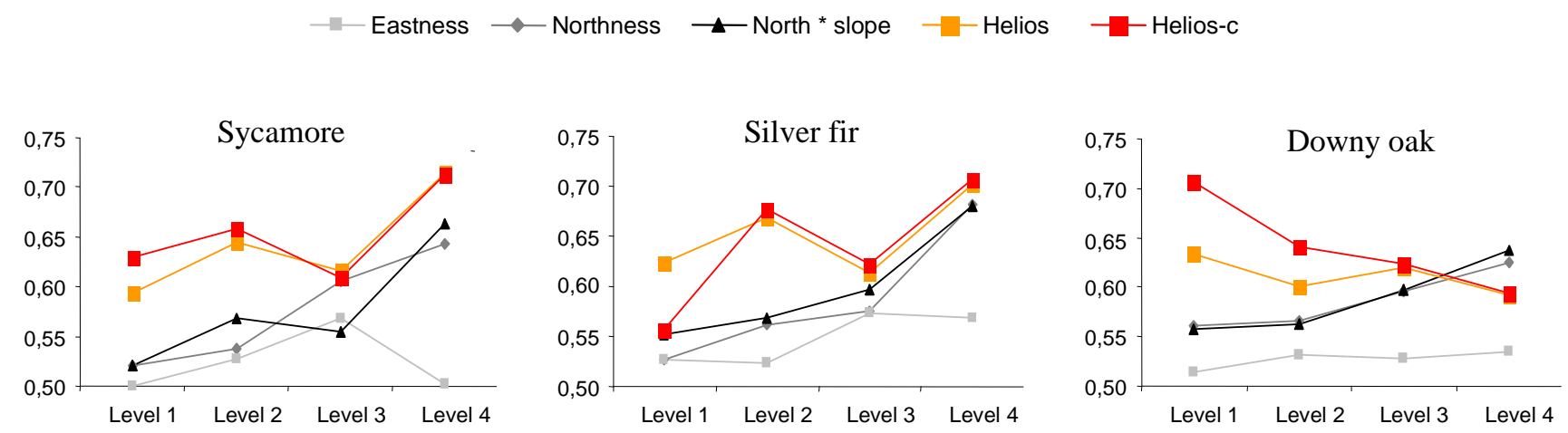

Figure 3.12: Mean AUC for the univariate models of distribution for sycamore, silver fir, and downy oak calculated on 4 different scales (Level $1=$ France, $550000 \mathrm{~km}^{2}$, level 2 $\approx 130000 \mathrm{~km}^{2}$, level $3 \approx 32000 \mathrm{~km}^{2}$, level $4 \approx 8000 \mathrm{~km}^{2}$ ). Eastness, northness, interaction between northness and slope, are successively evaluated, and compared with annual solar radiation for clear sky (Helios) and including cloud (Helios-c).

The response of sycamore, silver fir and downy oak fits better with monthly values of radiation during winter and summer months than with annual values (Figure 3.13). It corresponds to the winter and summer solstice periods (21st December and 21st June), i.e. the periods when the sun is at its lowest and highest positions. When the effect of cloud cover is removed, the summer effect disappears for sycamore and downy oak, for which AUC decreases from 0.72 to 0.55 for June. For silver fir, in contrast to the other species, the clear sky model performs better than the cloud cover model for most of the year, though not for the winter period.

The studied indices of solar radiation were used in combination with climate and soil variables in order to predict plant distribution on a national scale. We chose, for solar radiation, to select the synthetic annual values, and monthly calculations for June and December, these periods being identified as important in the preceding analysis. On a national scale, correlations were poor between solar radiation proxies and other environmental variables used to model species distributions. $\mathrm{R}^{2}$ ranged from $5.10^{-5}$ between $\mathrm{MaP}$ or $\mathrm{pH}$ and 
sine of aspect to 0.066 between $\mathrm{pH}$ and Helios-c for June. Solar radiation estimated with the Helios-c model was not linked to environmental predictors: $\mathrm{R}^{2}$ was 0.03 with MaT, 0.02 with altitude, and 0.003 with MaP. These low correlations ensure the absence of multicolinearity problems during the distribution modelling phase. The four variables are taken into account in monotonic or quadratic form in the downy oak and silver fir models, while altitude has no significant effect in the sycamore model.
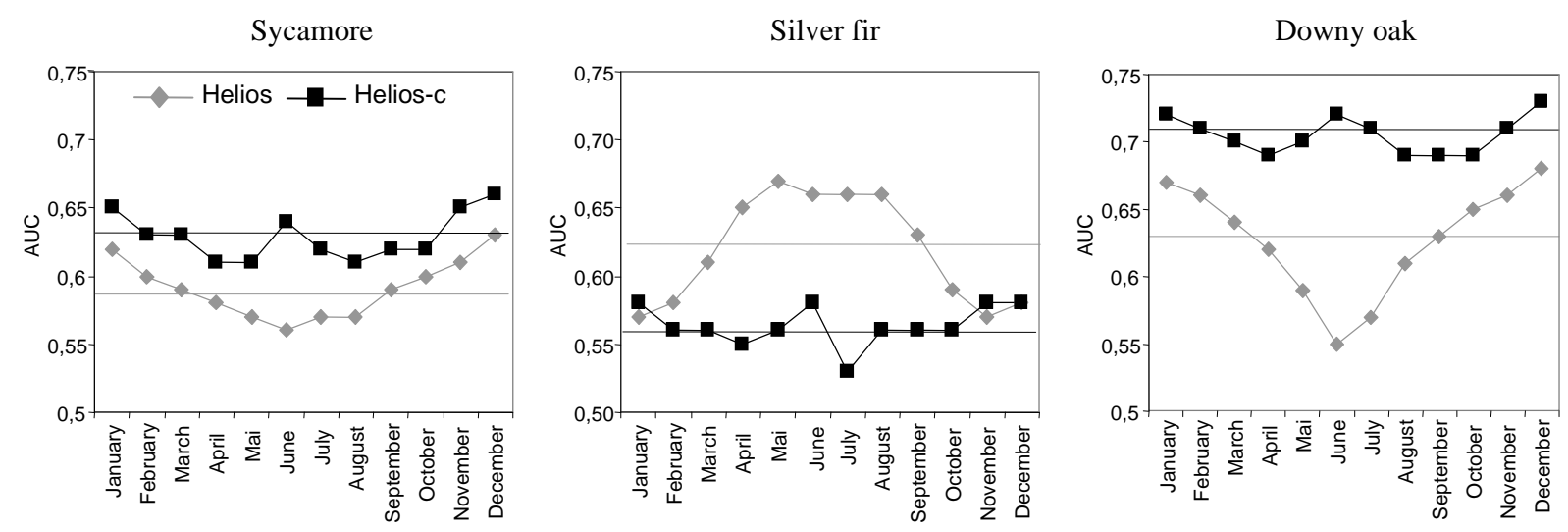

Figure 3.13: AUC of the distribution models of sycamore, silver fir and downy oak (n =6219) obtained on the scale of France with solar radiation estimated by the clear sky model (Helios) and cloud cover model (Helios-c). Horizontal lines represent annual values of AUC for the two models.

On a national scale, the environmental models including altitude, MaT, MaP, and $\mathrm{pH}$ were better predictors for downy oak and silver fir distribution (respectively AUC $=0.893$ and $\mathrm{AUC}=0.879$ ) than for sycamore (AUC $=0.795)$. The adding of slope-aspect transformations revealed only small effects, except for downy oak and silver fir where northness and interaction between northness and slope slightly increase the AUC (Figure 3.14). For the three species studied, the Helios model, with or without cloud cover, gave better results than slope-aspect transformation variables. The cloud cover model (Helios-c) always outperformed the clear sky one, including for silver fir for which predictive ability was worse than those of the clear sky model in the previous univariate analysis, probably due to correlations with the other environmental variables. Distribution models including annual values of solar radiation are less efficient than those including June or December values. Inclusion of a monthly value of overcast solar radiation (June or December) in the initial environmental model led to a statistically significant increase in AUC ( $\mathrm{p}<0.001$ ) from 0.795 to 0.825 for sycamore, 0.879 to 0.887 for silver fir, and 0.893 to 0.897 for downy oak. The choice of month (June or December) led to little change in the results, December giving better results for sycamore and June for silver fir and downy oak. 
The slope aspect transformations added on a local scale $\left(8000 \mathrm{~km}^{2}\right.$ area) to Helios radiation and other environmental variables resulted in a slight improvement in distribution models for downy oak with northness, increasing AUC by 0.006 ( $\mathrm{p}<0.05)$, and for sycamore with interaction of northness and slope which increase the model AUC by 0.007 ( $p<0.05$ ). When the scale increases, this effect became very weak on a regional level (considered areas $130000 \mathrm{~km}^{2}$ ), and the AUC improvement was less than 0.001 , although the effect of cosine of aspect with or without interaction with slope remained statistically significant for the three species $(\mathrm{p}<0.05)$.

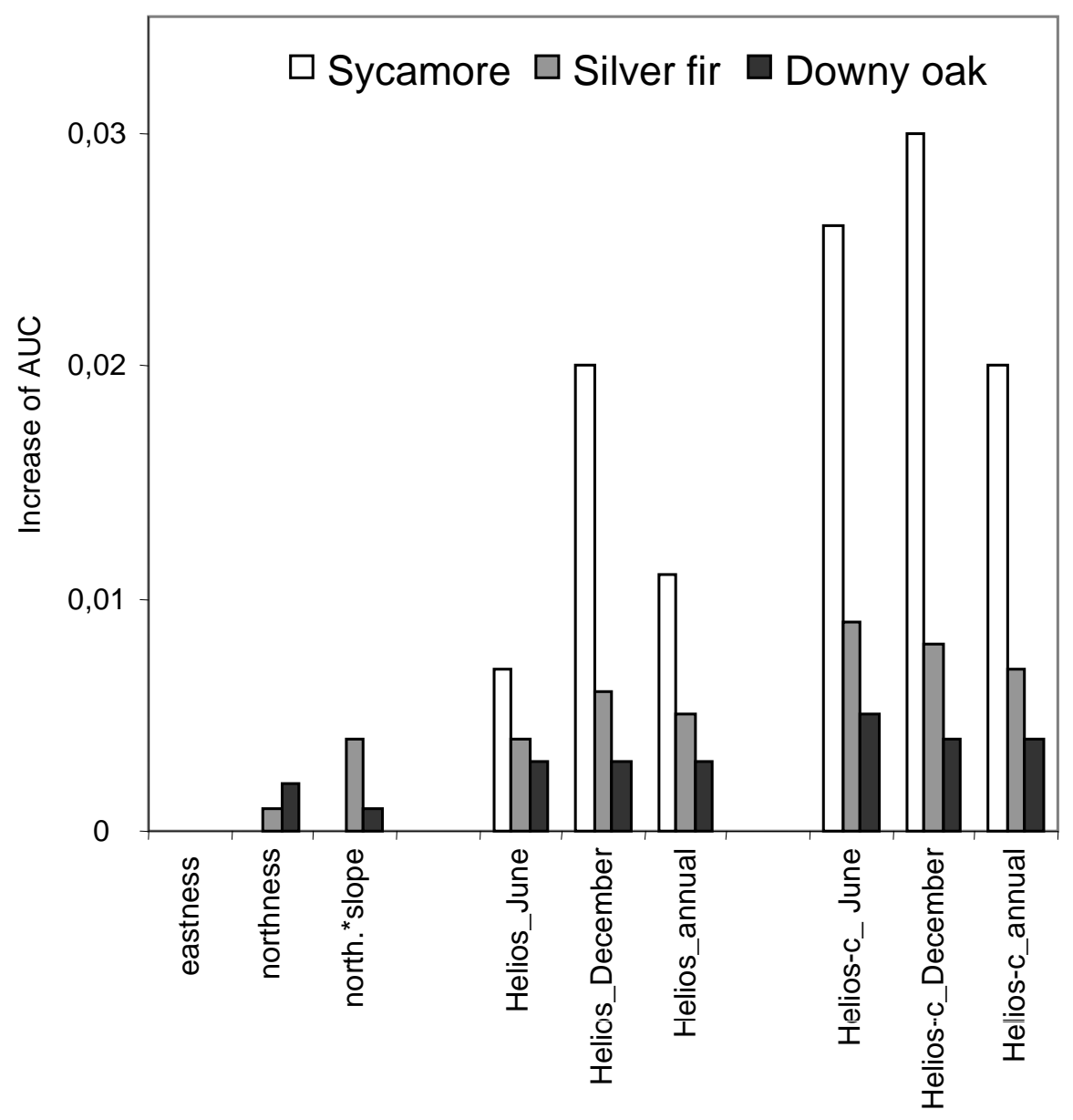

Figure 3.14 : Increase in AUC $(p<0.001)$ for sycamore, silver fir and downy oak distribution models derived for France including different proxies of solar radiation, as compared with the same models without solar radiation proxies. Each of the solar radiation indices was added to initial models including altitude, mean annual temperature, precipitation and soil $\mathrm{pH}$. 


\subsection{Discussion}

Ecologists have used many different methods to estimate solar radiation for studying plant species distribution, generally depending on data availability. The quality of biophysical maps is considered essential for improving plant modelling (Guisan and Zimmermann, 2000), and this study shows that large differences can occur in efficiency between the solar radiation proxies.

Comparison of solar radiation estimations shows that sine or cosine of aspect and interaction between slope and cosine of aspect have a very low correlation with measured solar radiation, unlike radiation values computed with the Helios model, which are strongly linked with those measured on the ground. However, the method of calculation greatly influences the results, and it appears essential to take extent of cloud cover into account in the elaboration of the radiation model: correlations with ground measurement are higher for the cloud cover model than for the clear sky one. The importance of cloud cover justifies the use of this variable on a large scale. This difference between models is more important in spring and summer, the clear sky model losing correlation with Météo France measurements in May and June. The low variability of solar radiation in summer (May, June and July) between aspects in mid-latitudes and the high variability of cloud cover for the same period probably explains why ground measurements are linked to overcast calculations $\left(\mathrm{R}^{2}=0.60\right.$ for June $)$ and not to clear sky ones $\left(\mathrm{R}^{2}=0\right.$ for June). Thus, cloud cover plays a fundamental role in differentiating regional patterns of solar radiation, and spring and summer GIS-based calculations of clear sky radiation are not representative of ground measurements over an extensive area like France. The use of these too high and homogeneous values of spring and summer radiations, estimated without cloudiness, can lead to an overestimation of PET in water balance models, and a smoothing of regional climates.

The ability to predict plant distribution for the 5 studied proxies is directly related to their efficiency in estimating measured values of solar radiation, the best correlated with Météo France ground measurements being also the most efficient in predicting vegetation patterns. On a national scale, the cloud cover model is then the most effective, whereas slope and aspect transformations improve only slightly or are not significant when they are included in the distribution models for the three species considered. The difference in predictive ability between the Helios-c model and the clear sky model or slope-aspect transformation is greater for large areas than on local scale. On a national scale, amplitude in latitude is large, and the same radiation value can be found in different conditions of slope and aspect. For example, a radiation value on the northern slopes of southern France could also be found on the southern slopes located further north, making the effect of topographical proxies very weak. This compensation of south-north effect on radiation by a change in latitude was observed for tree production in north America (Chen et al., 2002). Including temperature and precipitation, correlated with radiation when considering large areas, in the species distribution models partly removes this latitudinal effect and allows examination of the efficiency of topographical proxies. However, even in this case, the impact of these proxies remains low. On a local scale, correlation between slope-aspect transformations and solar radiation 
increases, because the length of gradients like latitude or cloud cover is low, and these modulators play a reduced role. We show that for an area of $8000 \mathrm{~km}^{2}$, GIS calculations overall perform slightly better than slope-aspect transformations. This explains how many studies carried out on smaller areas detect predictive ability in northness or eastness indices (Horsch, 2003; Kennedy and Spiesa, 2004; Lassueur et al., 2006; Fontaine et al., 2007; Gong et al., 2008). These results justify the choice of the cloud cover model for plant modelling for all the studied scales.

The evaluation of slope-aspect transformations combined with Helios-c values shows that plant distribution models can be slightly improved by slope-aspect variables on a local scale, even if the solar radiation effect is already taken into account. Other variables, like local climate, soil moisture, soil temperature, soil nutrient content, snow and wind vary with aspect and slope and can explain the cumulated effect of GIS radiation and slope-aspect transformations on a local scale, already observed by Austin (2005). On a wider scale this effect disappears probably because the link between topography and other environmental variables decreases. Furthermore, the smaller the area, the more limited the range of other ecological factors that determine the variability of species presence/absence, the main drivers of plant distribution on the local scale being linked to topographical effects. Then, slopeaspect transformations can be combined with solar radiation for plant modelling on a local scale.

Our study also shows an effect of the period when using GIS modelled solar radiation. Winter and summer solar radiation values are more relevant than annual values in predicting sycamore, silver fir and downy oak distribution. Summer values are linked to importance of drought for vegetation. The strong correlations of winter, and especially December, with species distribution has already been observed (Franklin et al., 2000), and may be linked to frost, metabolic activity or photosynthetic activity for evergreen species like silver fir (Garfi, 2000; Lebourgeois et al., 2005). They may also be related to the lower position of the sun over the horizon for this period, which increases the differentiation between north- and southfacing slopes (Franklin et al., 2000), involving correlations with other ecological variables influenced by changes of aspect, like soil moisture or local temperature. Finally, the better correlation of winter radiation with measured values as compared with radiation estimations of the rest of the year can also explain their importance. The efficiency of monthly values compared with annual ones, and their impact on plant physiology, justifies their use in plant distribution modelling.

With the development of modelling of plant or community distributions, there is an increasing need for readily available environmental descriptors over increasingly large areas. For the same ecological factor, the method of estimation must be carefully chosen and validated, to improve model predictions and to avoid misinterpretation. This assessment must 
consider scale dependence: for solar radiation, enlarging the size of the studied area reduces the correlation of slope and aspect transformations with plant species distribution and increases the value of GIS solar radiation including cloud cover. The use of a relevant method for solar radiation estimation, including both nebulosity and topographic features, should enhance the modelling of ecological factors at high resolution across geographical scales. Combined with other digital maps, they can be used to calculate derived variables, like spatially distributed actual evapotranspiration or water balance, which are key drivers of plant species growth and distribution, particularly in the context of the current climate change.

\section{References}

Aber, J.D. and Freuder, R., 2000. Variation among solar radiation data sets for the Eastern US and its effects on predictions of forest production and water yield. Climate Research, 15(1): 33-43.

Austin, M.P., 2002. Spatial prediction of species distribution: an interface between ecological theory and statistical modelling. Ecological Modelling, 157(2-3): 101-118.

Austin, M.P., 2005. Vegetation and environment : discontinuities and continuities. In: E.v. Maarel (Editor), Vegetation ecology. Blackwell publishing, Oxford, pp. 52-84.

Austin, M.P., Belbin, L., Meyers, J.A., Doherty, M.D. and Luoto, M., 2006. Evaluation of statistical models used for predicting plant species distributions : role of artificial data and theroy. Ecological Modelling, 199: 197-216.

Austin, M.P., Nicholls, A.O. and Margules, C.R., 1990. Measurement of the realised qualitative niche: Environmental niches of five Eucalyptus species. Ecological Monographs, 60(2): 161-177.

Benichou, P. and Le Breton, O., 1987. Prise en compte de la topographie pour la cartographie des champs pluviométriques statistiques. La Météorologie, 7(19): 23-34.

Brisse, H., de Ruffray, P., Grandjouan, G. and Hoff, M., 1995. European vegetation survey. The phytosociological database "Sophy". Part 1. Calibration of indicator plants. Part 2. Socio-ecological classification of the relevés. Annali di botanica, 53: 177-223.

Carroll, C., Zielinski, W.J. and Noss, R.F., 1999. Using presence-absence data to build and test spatial habitat models for the Fisher in the Klamath region, U.S.A. Conservation Biology, 13(6): 1344-1359.

Chen, H.Y.H., Krestov, P.V. and Klinka, K., 2002. Trembling aspen site index in relation to environmental measures of site quality at two spatial scales. Canadian Journal of Forest Research-Revue Canadienne De Recherche Forestiere, 32(1): 112-119.

Clark, D.B., Palmer, M.W. and Clark, D.A., 1999. Edaphic factors and the landscape-scale distributions of tropical rain forest trees. Ecology, 80(8): 2662-2675. 
Coudun, C. and Gegout, J.C., 2006. The derivation of species response curves with Gaussian logistic regression is sensitive to sampling intensity and curve characteristics. Ecological Modelling, 199(2): 164-175.

Coudun, C. and Gegout, J.C., 2007. Quantitative prediction of the distribution and abundance of Vaccinium myrtillus with climatic and edaphic factors. Journal of Vegetation Science, 18(4): 517-524.

Coudun, C., Gegout, J.C., Piedallu, C. and Rameau, J.C., 2006. Soil nutritional factors improve models of plant species distribution: an illustration with Acer campestre (L.) in France. Journal of Biogeography, 33(10): 1750-1763.

Diniz-Filho, J.A.F., Bini, L.M. and Hawkins, B.A., 2003. Spatial autocorrelation and red herrings in geographical ecology. Global Ecology \& Biogeography, 12: 53-64.

Dirnbock, T., Dullinger, S., Gottfried, M., Ginzler, C. and Grabherr, G., 2003. Mapping alpine vegetation based on image analysis, topographic variables and Canonical Correspondance Analysis. Applied Vegetation Science, 6: 85-96.

Dubayah, R. and Loechel, S., 1997. Modeling topographic solar radiation using GOES data. Journal of Applied Meteorology, 36(2): 141-154.

Dubayah, R. and Rich, P.M., 1995. Topographic Solar-Radiation Models for Gis. International Journal of Geographical Information Systems, 9(4): 405-419.

Duguay, C.R., 1993. Radiation modelling in mountainous terrain : review and status. Mountain research and development, 13: 339-357.

Elith, J., Graham, C.H., Anderson, R.P., Dudik, M., Ferrier, S., Guisan, A., Hijmans, R.J., Huettmann, F., Leathwick, J.R., Lehmann, A., Li, J., Lohmann, L.G., Loiselle, B.A., Manion, G., Moritz, C., Nakamura, M., Nakazawa, Y., Overton, J.M., Peterson, A.T., Phillips, S.J., Richardson, K., Scachetti-Pereira, R., Schapire, R.E., Soberon, J., Williams, S., Wisz, M.S. and Zimmermann, N.E., 2006. Novel methods improve prediction of species' distributions from occurrence data. Ecography, 29(2): 129-151.

Fielding, A.H. and Bell, J.F., 1997. A review of methods for the assessment of prediction errors in conservation presence/absence models. Environmental Conservation, 24(1): $38-49$.

Fontaine, M., Aerts, R., Ozkan, K., Mert, A., Gulsoy, S., Suel, H., Waelkens, M. and Muys, B., 2007. Elevation and exposition rather than soil types determine communities and site suitability in Mediterranean mountain forests of southern Anatolia, Turkey. Forest Ecology and Management, 247(1-3): 18-25.

Franklin, J., 1995. Predictive vegetation mapping: Geographic modelling of biospatial patterns in relation to environmental gradients. Progress in Physical Geography, 19: 474-499.

Franklin, J., 1998. Predicting the distribution of shrub species in southern California from climate and terrain-derived variables. Journal of Vegetation Science, 9(5): 733-748.

Franklin, J., McCullough, P. and Gray, C., 2000. Terrain variables used for predictive mapping of vegetation communities in Southern California. In: J.P. Wilson and J.C. Gallant (Editors), Terrain analysis: principles and applications. Wiley, New York. 
Garfi, G., 2000. Climatic signal in tree-rings of Quercus pubescens s.1. and Celtis austrialis L. in South-eastern Sicily. Dendrochronologia, 18: 41-51.

Gates, D.M. (Editor), 1980. Biophysical ecology, New York, 603 p. pp.

Gégout, J.C., Coudun, C., Bailly, G. and Jabiol, B., 2005. EcoPlant: a forest site database linking floristic data with soil and climate variables. Journal of Vegetation Science, 16(2): 257-260.

Gégout, J.C., Hervé, J.C., Houllier, F. and Pierrat, J.C., 2003. Prediction of forest soil nutrient status using vegetation. Journal of Vegetation Science, 14(1): 55-62.

Gong, X., Brueck, H., Giese, K.M., Zhang, L., Sattelmacher, B. and Lin, S., 2008. Slope aspect has effects on productivity and species composition of hilly grassland in the Xilin River Basin, Inner Mongolia, China. Journal of Arid Environments, 72(4): 483493.

Guisan, A., Theurillat, J.P. and Kienast, F., 1998. predicting the potential distribution of plant species in an alpine environment. Journal of vegetation science, 9: 65-74.

Guisan, A. and Thuiller, W., 2005. Predicting species distribution: offering more than simple habitat models. Ecology Letters, 8(9): 993-1009.

Guisan, A. and Zimmermann, N.E., 2000. Predictive habitat distribution models in ecology. Ecological Modelling, 135(2-3): 147-186.

Hetrick, W.A., Rich, P.M., Barnes, F.J. and Weiss, S.B., 1993. GIS based solar radiation flux models. American Society for photogrammetry and remote sensing technical papers, vol 3 GIS photogrammetry and modelling: pp123-143.

Hofierka, J. and Suri, M., 2002. The solar radiation model for Open source GIS: implementation and applications (2002), Open source GIS - GRASS User conference 2002, trento, Italy.

Horsch, B., 2003. Modelling the spatial distribution of montane and subalpine forests in the central Alps using digital elevation models. Ecological Modelling, 168(3): 267-282.

Kang, S.Y., Kim, S. and Lee, D., 2002. Spatial and temporal patterns of solar radiation based on topography and air temperature. Canadian Journal of Forest Research Journal Canadien de la Recherche Forestiere, 32(3): 487-497.

Kasten, F. and Czeplak, G., 1980. Solar and terrestrial radiation dependent of the amount and type of cloud. Solar energy, 24: 177-189.

Kennedy, R.S.H. and Spiesa, T.A., 2004. Forest cover changes in the Oregon Coast Rangefrom 1939 to 1993. Forest ecology and management, 200: 129-147.

Lassueur, T., Joost, S. and Randin, C.F., 2006. Very high resolution digital elevation models: do they improve models of plant species distribution? Ecological Modelling, 198(2): 139-153.

Lebourgeois, F., Bréda N., Ulrich E. and A, G., 2005. Climate-tree-growth relationships of European beech(Fagus sylvatica L.) in the French Permanent Plot Network (RENECOFOR). Trees Structure and Function, 19: 385-401. 
Lebourgeois, F. and Piedallu, C., 2005. Comment appréhender le niveau de sécheresse dans le cadre des études stationnelles et de la gestion forestière ? Notion d'indices bioclimatiques, méthode d'estimation de l'évapotranspiration potentielle. Assessing drought severity for the purposes of ecological studies and forest management using bioclimatic indices. Revue forestière Française, LVII, volume 4/2005: p331-356.

McCullagh, P. and Nelder, J.A., 1997. Generalized linear models. Monographs on Statistics and Applied Probability, 37. Chapman \& Hall, London, UK, 511 pp.

Meentemeyer, R.K., Moody, A. and Franklin, J., 2001. Landscape-scale patterns of shrubspecies abundance in California chaparral: The role of topographically mediated resource gradients. Plant Ecology, 156: 19-41.

Miller, J. and Franklin, J., 2002. Modeling the distribution of four vegetation alliances using generalized linear models and classification trees with spatial dependence. Ecological Modelling, 157(2-3): 227-247.

Moser, D., Dullinger, S., Englisch, T., Niklfeld, H., Plutzar, C., Sauberer, N., Zechmeister, H.G. and Grabherr, G., 2005. Environmental determinants of vascular plant species richness in the Austrian Alps. Journal of Biogeography, 32(7): 1117-1127.

Piedallu, C. and Gégout, J.C., 2007. Multiscale computation of solar radiation for predictive vegetation modelling. Annals of Forest Science, 64: 899-909.

Pierce, K.B., Lookingbill, T. and Urban, D., 2005. A simple method for estimating potential relative radiation (PRR) for landscape-scale vegetation analysis. Landscape Ecology, 20(2): 137-147.

Rameau, J.C., Mansion, D. and Dumé, G., 1989. Flore forestière française - guide écologique illustré - tome 1 : plaines et collines. Institut pour le Développement, Paris, 1785 pp.

Rameau, J.C., Mansion, D. and Dumé, G., 1993. Flore forestière française - guide écologique illustré - tome 2 : montagnes. Institut pour le Développement, Paris, $2421 \mathrm{pp}$.

Rich, P.M., Hetrick, W.A. and Savings, S.C., 1995. Modeling topographic influences on solar radiation: a manual for the SOLARFLUX model., Los Alamos National Laboratory Report LA-12989-M, Los Alamos, New Mexico, USA.

Satterlund, D.R. and Means, J.E., 1978. Estimating solar radiation under variable cloud conditions. Forest science, 24: 363-373.

Tappeiner, U., Tasser, E. and Tappeiner, G., 1998. Modelling vegetation patterns using natural and anthropogenic influence factors: preliminary experience with a GIS based model applied to an Alpine area. Ecological Modelling, 113(1-3): 225-237.

Thuiller, W., Vayreda, J., Pino, J., Sabate, S., Lavorel, S. and Gracia, C., 2003. Large-scale environmental correlates of forest tree distributions in Catalonia (NE Spain). Global Ecology and Biogeography, 12(4): 313-325.

Wilson, J.P. and Gallant, J.C., 2000. Terrain analysis, principles and applications. John Wilay and sons, $479 \mathrm{pp}$. 
Yang, K., Koike, T. and Ye, B.S., 2006. Improving estimation of hourly, daily, and monthly solar radiation by importing global data sets. Agricultural and Forest Meteorology, 137(1-2): 43-55.

Zimmermann, N.E. and Kienast, F., 1999. Predictive mapping of alpine grasslands in Switzerland: Species versus community approach. Journal of Vegetation Science, 10(4): 469-482. 
